$\mathrm{EI} / 30$

ISSN 0969-4447

\title{
Enforcing Intellectual Property Rights
}

\author{
Jean O. Lanjouw
}

And

\section{Mark Schankerman}

Contents:

Abstract

1. Introduction

2. Analytical Framework

3. Description of Data

4. Non-Parametric Evidence

5. Econometric Analysis

6. Concluding Remarks

Appendices

References

$\mathrm{EI} / 30$

December 2001

The Toyota Centre

Suntory and Toyota International Centres for Economics and Related Disciplines

London School of Economics and Political Science

Houghton Street

London WC2A 2AE

Tel: (020) 79556674

This paper was prepared for the Conference on New Research on the Operation of the Patent System, sponsored by the U.S. National Academy of Sciences in Washington (October 2001). We thank the National Academy of Sciences and the Brookings Institution for financial support and Derwent for generously providing access to the detailed patent information for their LitAlert data base, which was critical to making this project feasible. We also thank Bronwyn Hall and Adam Jaffe for their input and provision of data. Joe Cecil from the Federal Judicial Center and Jim Hirabayashi of the U.S. Patent and Trademark office for helpful discussions about the court and patent data, as well as Marty Adelman, Kimberley Moore, and seminar participants at the National Academy of Sciences, the University of Maryland, Wharton and Berkeley for useful comments. Maria Fitzpatrick provided excellent research assistance. 


\begin{abstract}
We study the determinants of patent suits and their outcomes over the period 19781999 by linking detailed information from the U.S. patent office, the federal court system, and industry sources. The probability of being involved in a suit is heterogeneous, being much higher for valuable patents and for patents owned by individuals and smaller firms. Thus the patent system generates incentives, net of expected enforcement costs, that differ across inventors. Patentees with a large portfolio of patents to trade, or having other characteristics that encourage "cooperative" interaction with disputants, more successfully avoid court actions. At the same time, key post-suit outcomes do not depend on observed characteristics. This is good news: advantages in settlement are exercised quickly, before extensive legal proceedings consume both court and firm resources. But it is bad news in that the more frequent involvement of smaller patentees in court actions is not offset by a more rapid resolution of their suits. However, our estimates of the heterogeneity in litigation risk can facilitate development of private patent litigation to mitigate this adverse effect of high enforcement costs.
\end{abstract}

Keywords: Patents, Court Actions, Settlement.

JEL Classification Number: K41

(C) by Jean O. Lanjouw* and Mark Schankerman.** * Deparment of Economics, Yale University, P. O. Box 208264, New Haven, CT 06520-8264 and the Brookings Institution, e-mail: lanjouw@econ.yale.edu. ** Department of Economics, London School of Economics and Political Science, Houghton Street, London WC2A 2AE, UK, e-mail: m.schankerman@1se.ac.uk. All rights reserved. Short sections of text not to exceed two paragraphs may be quoted without explicit permission provided that full credit, including (C) notice is given to the source. 


\section{Introduction}

Patent litigation grew rapidly during the period 1978-1999. The number of patent suits rose by almost tenfold, with much of this increase occurring during the 1990's. This has raised fears among scholars and the business community that "patent thickets" are beginning to impede the ability of firms to conduct R\&D activity effectively (Eisenberg, 1999; Shapiro, 2001). But focusing on the level of litigation is misleading. We show that the the growth in patenting has been comparable to the growth in litigation, with the consequence that filing rates for suits have been roughly constant over these two decades. The average rate is relatively low, 19.0 suits per thousand patents. But this too is misleading, because exposure to litigation varies widely across technology fields and patent profiles. Average suit rates vary from a low of 11.8 per thousand chemical patents to 25-35 per thousand computer, biotechnology and non-drug health patents. Moreover, within any given technology field, probabilities of litigation differ very substantially, and are systematically related to patent characteristics associated with their economic value and to characteristics of their owners.

This heterogeneity of patents, and their owners, is a central issue for the enforcement of intellectual property rights and its economic consequences. Lerner (1995), for example, provides evidence that small firms avoid R\&D areas where the threat of litigation from larger firms is high. Lanjouw and Lerner (2002) argue that the use of preliminary injunctions by large firms can discourage $R \& D$ by small firms, and this may apply to other legal mechanisms. Even if parties can settle their patent disputes without resorting to suits, the effective threat of litigation will influence settlement terms and thus, ultimately, the incentives to undertake R\&D. The essence of the process of enforcing patent rights is sorting, or selection, among patent disputes. In theoretical models of litigation (P'ng, 1983; Bebchuk, 1984; Priest and Klein, 1984; Spier, 1992), this sorting can occur at each stage of the legal process, beginning with the decision to file a suit and ending either with post-suit settlement or adjudication at trial. Using a comprehensive new data set covering all recorded patent litigation in the U.S. over the period 1978-1999, we analyse the determinants of this sorting process.

One of our key empirical findings is that virtually all of the sorting on observed characteristics of both patents and their owners occurs in the decision to file suits. The 
key post-suit outcomes - the probability of settlement and the plaintiff win rates at trial - are almost completely independent of these characteristics. The threat of court action (suits) is the primary mechanism through which sorting occurs, and this helps to mitigate the private (and social) costs of enforcement. This conclusion is reinforced by two additional findings: first, post-suit settlement rates are high (about 95 percent) and, second, most settlement occurs soon after the suit is filed, often before the pre-trial hearing is held.

There are two main mechanisms by which patentees can settle disputes without resorting to litigation. The first is by "trading" intellectual property. This take various forms, including cross-licensing agreements and patent exchanges, sometimes with balancing cash payments (Grindley and Teece, 1997). One motivation for accumulating patents may be to facilitate such trading (Hall and Zeidonis, 2001). The second mechanism that promotes settlement of disputes is the expectation of repeated interaction among patentees. The theory of supergames, especially under incomplete information, suggests that repeated interaction increases both the ability (players learn about each other's unobserved type) and the incentive to settle disputes "cooperatively" - i.e., without filing suits (see, for example, Bernheim and Whinston, 1990). But there is very little econometric evidence to support this prediction. ${ }^{2}$

The importance of trading and repeated interaction as mechanisms for patent dispute resolution is supported by three key findings in this paper. First, we find strong evidence of a patent portfolio effect in enforcing patent rights: having a larger portfolio of patents reduces the probability of filing a suit on any individual patent, conditional on its observed characteristics. And the quantitative effect is large. For a (small) domestic unlisted company with a small portfolio of 100 patents, the average probability of litigating a given patent is two percent. For a similar company but with a moderate portfolio of 500 patents, the figure drops to only 0.5 percent. This portfolio effect means that there are beneficial "enforcement spillovers" across patents within a given firm, conferring advantages to size in the ability of firms to appropriate returns from their intellectual property. Second, we find that the (marginal) effect of patent portfolio size is stronger for smaller companies, as measured by employment. For small firms, having a portfolio of patents to "trade" is likely to be the key mechanism for avoiding litigation, whereas larger firms can also rely on repeated interaction in intellectual property and

\footnotetext{
${ }^{2}$ A notable exception is Siegelman and Waldfogel (1999) who construct measures of repeat play and find evidence that reputation matters in various areas of litigation.
} 
product markets to discipline behaviour. Third, firms which operate in technology areas that are more concentrated (where patenting is dominated by fewer companies) are much less likely to be involved in patent infringement suits. In short, what is important for settlement is that firms either have a portfolio of intellectual property to trade, or have other dimensions of interaction that promote "cooperative" behavior. In addition to the ability to trade patents and repeated play, we find that asymmetry of firm size affects litigation risk. Patent owners who are large relative to disputants they are likely to encounter less frequently resort to the courts to settle disputes.

We also show the characteristics of a given patent strongly affect litigation risk in ways that are consistent with existing hypotheses in the economics literature (as in Lanjouw and Schankerman, 2001). We illustrate this with two example. First, more valuable patents, as measured by the number of claims and citations per claim, are much more likely to be involved in suits. Second, patents that are related to subsequent technological activity by the firm (cumulative innovation), as measured by the extent of self-citation in patents, are more likely to be litigated. This supports the idea that complementarity among inventions increases the willingness to protect the property rights, especially the key (early) innovations in the chain (Scotchmer, 1991). We show that differences in these, and other, patent characteristics lead to wide variations in the probability of litigation, within any given technology field.

Both the advantages of patent portfolio and company size in settling disputes, and the heterogeneity of litigation risk across patents, point to the potential importance of developing market-based provision of patent litigation insurance. This may be essential for strengthening the ability of small firms to enforce their intellectual property rights, and their bargaining power in negotiated settlements. There are a number of providers of litigation insurance in the U.S. and other countries. But the effective demand has been severely limited by high prices while, at the same time, profitability for suppliers is undermined by the widespread use of pooled prices. Some of these concerns have recently been voiced in government and the public media. ${ }^{3}$ The results in this paper can be used to develop insurance pricing schemes that recognise the (observed) heterogeneity of litigation risk. From the perspective of small firms, this is a double-edged sword. By facilitating economically rational price differentiation, such information may make it

\footnotetext{
${ }^{3}$ For an interesting policy discussion of past experience in this area, see the Danish Ministry of Trade and Industry (2001) report. A recent media story appeared in the U.K. Financial Times (September $14,2001)$.
} 
easier to establish sustainable insurance markets. On the other hand, the advantages to portfolio and company size in reducing litigation risk suggest that the appropriate prices for smaller firms should be higher than for large firms, for any given patent profile. But both small and large firms have patents of many profiles, and differentiating pricing across patent characteristics is likely to be beneficial to both types of firms.

The paper is organised as follows. Section 2 summarises the analytical framework, including the litigation stages and outcomes we analyse. Section 3 describes the construction of the data set, summarises the main characteristics of patents and their owners on which we focus, and discusses how they relate to economic hypotheses about the determinants of litigation. Section 4 presents and discusses non-parametric evidence on the relationship between these characteristics and the filing of suits and their outcomes. Section 5 presents econometric analysis of the determinants of litigation for infringement and invalidity suits, and of post-suit settlement. Concluding remarks summarise directions for future research.

\section{Analytical Framework}

For analytical purposes, we break down the litigation process into four stages: 1. filing the suit, 2. the pre-trial hearing, 3. commencement of the trial, and 4. adjudication at the conclusion of trial. According to our discussions with patent lawyers, legal costs are more closely related to how many stages the case reaches than to the actual length of the case, which is strongly affected by the availability of court resources and other external factors.

There are three possible outcomes to a suit: 1 . settlement, 2 . win for the plaintiff, or 3. win for the defendant (the identity of the patentee depends on whether it is an infringement or invalidity suit). ${ }^{4}$ If a patent dispute is settled before a suit is filed, we do not observe the dispute in the data. Thus low filing rates can either reflect low rates infringement (disputes) or high probability of pre-suit settlement. After a suit is filed, settlement can occur before the pre-trial hearing, after the hearing but before the trial begins, or during the trial. Otherwise, the trial concludes with a court judgement in

\footnotetext{
${ }^{4} \mathrm{~A}$ win for both parties can arise, e.g., infringement suits when there is a counter-claim for invalidity by the defendant. The court may rule that infringement occurred but strike down the validity of some of the patent claims. When a win for both parties is recorded, we count it both for the plaintiff and the defendant rather than as a separate category.
} 
favour of one of the parties. ${ }^{5}$.

Lanjouw and Schankerman (2001) analysed the determinants of the probability of litigation (case filings). For this paper we have constructed a larger data set that allows us to study both case filings and post-suit outcomes. In particular, we analyse:

1. the probability of a suit being filed

2. the probability of settlement, conditional on a suit being filed

3. the timing of settlement: i.e., the conditional probability that the suit is resolved before the pre-trial hearing or after.

4. the plantiff win rates, conditional on adjudication at trial.

Information on win rates is relevant for assessing overall litigation risk (e.g., in pricing patent insurance). Such information is also useful in testing competing economic models of litigation because the models generate different predictions about plaintiff win rates at trial (Walfogel, 1998; Siegelman and Waldfogel, 1999). There are two main models: divergent expectations (Priest and Klein, 1984) and asymmetric information (Bebchuk, 1984). In the divergent expectations model, each party estimates the quality of his case (equivalently, the relevant legal standard) with error, and cases go to trial when the plaintiff is sufficiently more optimistic than the defendant. This is most likely to occur when true case quality is near the court's decision standard. This selection mechanism drives the plaintiff win rate at trial toward 50 percent. ${ }^{6}$ In the asymmetric information model, one party knows the probability that the plaintiff will win at trial, while the other party knows only the distribution of plaintiff win rates. The uniformed party makes a settlement offer (or a sequence of offers, in dynamic versions of the model Spier 1992) and it will be accepted only by informed defendants who face a relatively low probability of winning at trial. Trials can arise in equilibrium because settlement offers have some probability of failing when one of the parties has private information. Because of this one-sided selection mechanism, the asymmetric information model predicts that the win rate for the party with private information should tend toward 100 percent. As we discuss in Section 4, the empirical evidence for patent litigation strongly favors the

\footnotetext{
${ }^{5}$ Apart from settlement, the court may dismiss the case prior to trial without request of one of the parties. We drop these cases from the sample. In this paper we do not distinguish different forms of adjudication, such as court verdicts, jury verdicts and directed verdicts.

${ }^{6}$ If parties have differential stakes (e.g., one firm also gets reputation gains from winning), the divergent expectations model predicts higher win rates for the party with higher stakes.
} 
divergent expectations model.

Litigation models explain why cases reaching trial are a selected sample of filed cases. Similar selection will be at work on filed cases, to the extent that potential plaintiffs may not file suits on certain types of patents (or defendants may settle prior to suit). Lanjouw and Schankerman (2001) show that observed characteristics of patents and their owners strongly affect the probability of filing a suit. We confirm, and extend, those findings in this paper. At the same time, we find that post-suit outcomes - e.g., whether parties settle, or who wins if the case reaches trial - are unrelated to these same characteristics.

\section{Description of Data}

The data source used to identify litigated patents is the LitAlert database produced by Derwent, a private vendor. This database is primarily constructed from information collected by the U.S. Patent and Trademark Office (PTO). The data used include 13,625 patent cases filed during the period 1978-1999. Each case filing identifies the main patent in dispute, although there may also be other patents listed. We use only the main listed patent in our analysis, for reasons explained later. There are 9,345 patents involved in our sample of suits.

We also obtained information on all U.S. patent-related cases (those coded 830) from the court database organised by the Federal Judicial Center (FJC). This information runs through the end of 1997 and includes the progress or resolution of suits - e.g., whether the case is settled and at which stage of the proceedings this occurs, whether the case proceeds to trial, and the outcome of the trial. ${ }^{7}$ The form of docket numbering was made (by hand) consistent across the two data sets, so they could be merged.

To create a control group, we generated a "matched" set of patents from the population of all U.S. patents (both litigated and unlitigated) from the PTO. For each litigated patent, a patent was chosen at random from the set of all U.S. patents with the same application year and primary 3-digit U.S. Patent Classification (USPC) class assignment. By constructing the population sample in this way, the comparisons we

\footnotetext{
${ }^{7}$ Discussions with the Federal Judicial Center indicated the data probably do not cover all cases involving patents, as some may be coded under other categories by the court (e.g., the patent issue may be part of a broader contractual dispute). This is also evident in the data where a small percentage of cases identified in Derwent are not in the FJC database (see Somaya, 2001, for a breakdown between typos and coding differences). But there is no reason to expect any selection bias from the perspective of the issues we analyse.
} 
present between litigated patents and matched patents largely control for technology and cohort effects. The control is not perfect, however, because we have 12,771 matched patents. This is bigger than the number of litigated patents for two reasons. First, the more recent part of our sample includes matches for both main and other patents in each suit, whereas we only use the main litigated patents in the analysis. Second, in combining our old (1978-91) and new (1990-99) data, we dropped duplicate cases in the overlapping years when counting litigated patents. We do not have identifiers in either round of subsetting the litigated data that would allow us to easily delete the corresponding matched patents. We do not expect this to create any systematic bias.

Although the U.S. Federal courts are required to report to the PTO every case filing that involves a U.S. patent, under-reporting occurs in practice. Thus the PTO (and Derwent) data is a subset of all patent cases. To estimate the reporting rates, we take the number of cases filed according to Derwent divided by the number in the same year that are coded as a patent case by the Federal Judicial Center. We can compute the reporting rates through 1998 (we use the last value for 1999). They stabilise in the 1990's at about 55 percent (see Appendix 1). We found no evidence of selection bias in the underreporting by the courts to the PTO: there are no significant differences between reported and unreported cases for a range of variables in the federal database.

A truncation issue arises because we observe suit filings only through 1999, so later cohorts of patents look like they are less litigated by construction. We use the lag structure for case filings for cohorts 1982-86 to adjust for this truncation. The estimates are based on the pooled sample, and are applied to each technology field. The truncation rate for the 1992 cohort (i.e., lag of 7 years) is about 50 pecent, and it jumps sharply to 75 percent for the 1995 cohort. Appendix 1 presents the estimated truncation rates.

From the main PTO database we obtained information on the following characteristics for each litigated and matched patent:

Number of Claims: A patent is comprised of a set of claims which delineates the boundaries of the property rights provided by the patent. The principal claims define the essential novel features of the invention in their broadest form and the subordinate claims are more restricted and may describe detailed features of the innovation claimed. The patentee has an incentive to claim as much as possible in the application, but the patent examiner may require that the claims be narrowed before granting.

Technology Field: Each patent is assigned by the patent examiner to 3-digit classes 
of the USPC system, of which there are 421 in total. The USPC is a heirarchical, technology-based classification system and patents may be assigned to more than one class. In the empirical analysis, we use the set of all 3-digit classes to which a patent was assigned. We use the categorisation developed by Adam Jaffe to aggregate these classes to a 2-digit level (used for some purposes explained later) and then to the eight broad technology groups used in most of the paper: Drugs, Other Health, Chemical, Electronics (excl. computers), Mechanical, Computers, Biotechnology, and Miscellaneous. Assignments to biotechnology are based on the categorisation used by the PTO when determining who examines a patent. The technology field composition of cases is given in Table 1.

Citations: An inventor must cite all related prior U.S. patents in the patent application. A patent examiner who is an expert in the field is responsible for insuring that all appropriate patents have been cited. Like claims, the citations in the patent document help to define the property rights of the patentee. For each patent in the litigated and matched data, we obtained the number of prior patents cited in the application (backward citations) and their USPC sub-class assignments. We obtained the same information on all subsequent patents which had cited a given patent in their own applications, as of 1998 (forward citations). For recent patents there is substantial truncation in the number of forward citations, since citation lags can be long (Jaffe and Trajtenberg, 1999). To minimise truncation bias, we limit parts of the analysis to cohorts before 1993. For older patents there is considerable missing information on the USPC sub-class assignments of backward citations, as comprehensive data are only available from about 1970, but the number of backward citations is complete for all patents.

Ownership: We identify each patent owner as an individual, an unlisted company, or a listed company. ${ }^{8}$ Individual and firm owners are indicated as such in the PTO data. Bronwyn Hall and Adam Jaffe were generous in providing us with their link between PTO company codes and Standard and Poors' CUSIP identication code, based on the 1989 industry structure. We call a patent-owning company "listed" if we are able to identify it as having a Standard and Poor's CUSIP code at that time. ${ }^{9}$ Unlisted

\footnotetext{
${ }^{8} \mathrm{~A}$ small share of patents is assigned to institutions, such as universities, hospitals or governments. We treat these as unlisted companies.

${ }^{9}$ Two points are worth noting here. First, companies that merge after 1989 stop accumulating patent portfolios because their subsequent patenting is listed under a different (merged company) code. Second,
} 
companies are typically smaller than listed ones, but there is wide variation in both categories. Individuals and listed companies are more predominantly domestic (81.0 and 95.6 percent, respectively) than unlisted companies (60.4 percent). We also break down listed firms into "large" firms (those with employment above the median of 5425) and "small" firms with employment below the median. Unless otherwise noted, we classify the nearly 40 percent of firms without employment data as large firms because they have similar litigation and settlement patterns.

Nationality: We use the PTO designation of companies as domestic or foreign if there is an assignee, and the address of the first listed inventor if there is no assignee. Domestic patents account for 73.4 percent of the total.

Case Type: We manually matched the owner of each litigated patent to the appropriate party in the suit (plaintiff, defendant, neither). We identify a filed case as an infringement suit if the patent owner is a plaintiff, and as a suit for a declaratory judgment if the patent owner is a defendant. This could be done for about 65 percent of the suits. For those cases, infringement suits account for about 85 percent of the total. In most of the analysis we treat those suits where the patentee is not one of the litigants as an infringement suit, since they are likely to be suits brought either by an exclusive licensee or by a subsidiary or head office of the patent-owning entity.

Patent Portfolio Size: Each company that is assigned a patent by the inventor is given a company code by the PTO. This allows us to construct a measure of the size of an owner's patent portfolio, as it looks around the application date of each of our sample patents. The relevant portfolio variable (portsize) is defined as the number of patents owned by a company that have an application date within ten years in either direction of the patent in question. Notice that this portfolio size variable may differ across patents, for a given company. As expected, domestic listed companies tend to have larger portfolios - roughly a third of patents owned by domestic listed companies are in portfolios in each of size groups 1-100, 100-900 and >900 patents. By contrast, about 90 percent of patents owned by domestic unlisted companies, and two-thirds of patents owned by foreign companies, are in portfolios with fewer than 100 patents.

Technology Concentration: We construct a measure of firm concentration in the

any listed company that is started after 1989 will not have a CUSIP in our data and thus will be coded as an unlisted company. 
technology area of each patent. To do this, we first construct, for each 2-digit USPC class, a four-firm concentration index, measured as the patenting share of the top four firms. A firm's share is the size of its patent portfolio in that class divided by the sum of all firms' patents in that class. For each patent we then construct a weighted average of the concentration indices for the different classes, where the weights are the shares of the forward citations to the patent that fall in that technology class. Formally, let $Z_{f}^{c}$ be the portfolio size for firm $f$ in technology class $c$ (including all patents since 1978) and $Z^{c}$. $=\sum_{f} Z_{f}^{c}$. The concentration index for the class is $C 4^{c}=\sum_{f} Z_{f}^{c} / Z^{c}$, where the sum is over the top four firms in terms of shares in that class. The weighted technology concentration index for patent $i$ is $C 4_{i}=\sum_{c} w_{i}^{c} C 4^{c}$ where $w_{i}^{c}=F_{i}^{c} / F_{i}$ is the fraction of the forward citations to patent $i$ that fall into technology class $c$. If a company operates in more concentrated technological areas, it faces a greater chance of encountering other firms in patent disputes more than once. This expectation of repeated interaction should lower the litigation rate (i.e., promote pre-suit settlement).

Relative Size: We construct a measure of the asymmetry in portfolio size between a patentee and the "representative" disputant he can expect to face on each patent. Relative portfolio size is defined as the firm's total portfolio size (including all patents since 1978) divided by a weighted average of the portfolio size of firms in classes from which its forward citations come. Formally, let $Z_{f}=\sum_{c} Z_{f}^{c}$ be the portfolio size for firm $f$, and $\bar{Z}^{c}=Z^{c} / n_{c}$ be the average portfolio size of the $n_{c}$ firms with patents in class c. The relative portfolio size of firm $f$ for patent $i$ is $R_{i f}=Z_{f} / \sum_{c} w_{i}^{c} \bar{Z}^{c}$, . where $w_{i}^{c}$ is defined as above.

For a patentee who is the plaintiff (infringement suits), being relatively large confers greater threat power (e.g., holding cross-licensing of other patents hostage to this dispute) and this should facilitate settlement with the infringer. This is less clear-cut when the patentee is the defendant. A stronger defendant may be less willing to settle (or be able to extract more favorable settlement terms from the plaintiff). Thus we expect the probability of litigation to decline with relative size in infringement suits, but the prediction for declaratory judgement suits is ambiguous.

Other Information: From Standard and Poors' information on listed companies, we downloaded financial and other company information for the listed firms either owning patents involved in litigation or in our matched sample.

The preceding variables are designed to capture the main determinants of patent 
suits: $^{10}$ (i) the number of potential disputes - measured by the number of claims, the diversity of technology classes into which the patent falls, and the technological similarity of future patents that cite the original one; (ii) the size of the stakes - measured by the number of future citations the patent receives, and the extent of self-citation (as an indicator of the firm's cumulative investment in that technology); and (iii) the relative costs of settlement and prosecuting a suit - measured by patent portfolio size, technology concentration, relative size, and ownership type and nationality of the patentee.

\section{Non-parametric Evidence}

Although the number of patent infringement suits has risen by almost tenfold since 1978, the increase has not been uniform across technology fields - it was particularly high in Drugs, Biotechnology, Computers and Other Electronics. Closer examination of the data shows that the increase in the aggregate number of suits has been driven both by the sharp increases in the number of patent applications in each technology field and by the shift of patenting toward technology fields with higher litigation rates. The total number of patent applications grew by 71 percent over the period, but in Drugs, Biotechnology, and Medical Instruments patenting nearly tripled, and in Computers it grew by four-fold. Once the growth in patenting is taken into account, we find that there has been no trend increase in the filing rates of suits in any technology field over this period.

Table 2 presents estimates of average filing rates for three sub-periods: 1978-84, 1985-90 and 1991-95. We measure filing rates as the number of suits filed per thousand patents from a given cohort. ${ }^{11}$ These include all of the suits filed in connection with these patents through 1999 (i.e., we count multiple cases for the same patent), and they are adjusted both for under-reporting in the Derwent data and truncation associated with time lags in case filings. ${ }^{12}$

\footnotetext{
${ }^{10}$ For a good, general discussion of the economic determinants of litigation, see Cooter and Rubinfeld (1989).

${ }^{11}$ We do not compute rates based on filing year for two reasons: 1 . the population of patents alive at any date (the denominator of the filing rate) is unknown since it depends on the pattern of patent renewals for the preceding twenty cohorts, and 2. the age structure of the population changes over time as patenting rates increase, and age and filing rates are related.

${ }^{12}$ Given the acceleration of patenting activity, the stock of patents grew more slowly than the flow during this period, so that the number of filed cases relative to the stock of patents did rise (not
} 
The table also shows that mean filing rates vary substantially across technology fields. A formal test that the filing rates are the same across fields is strongly rejected $\left(\chi^{2}(7)=1,103 ; \mathrm{p}\right.$-value <.001). For the aggregate (pooled technology field) data, there are 19.0 case filings per thousand patents. The lowest rates are found in Chemicals (11.8), Electronics (15.4) and Mechanical (16.9). Interestingly, filing rates for pharmaceutical patents are only modestly higher than the average. The filing rates are much higher for patents in Other Health, Computers, Biotechnology, and Miscellaneous.

While we observe little evidence of trends in filing rates, the level of filing rates may be understated by Table 2 . They are caculated using only the main patents in each suit, while there may in fact be several patents per suit. We present these calculations because, for filing years before 1990, we only have information about the main patents (mixing the subsidiary patents for later years would distort litigation trends). The filing rates we compute are underestimates of the "true" rates if one views being a subsidiary patent in a case as equivalent to being the main litigated patent. To estimate the difference, one could scale up the filing rate by dividing by the ratio of subsidiary to main patents. This ratio is 0.24 percent overall, but it varies across technology fields. ${ }^{13}$

It is important to look beyond average filing rates for given technology fields, because they conceal huge heterogeneity. Lanjouw and Schankerman (2001) showed that litigated patents have more claims and more forward citations per claim. Table 3 confirms this finding on the larger data set. The table presents the mean number of claims, and citations per claim, for litigated and matched patents, broken down by ownership type. Litigated patents have far more claims than matched patents, and this holds for each ownership type. They also have more forward citations per claim and fewer backward cites per claim (i.e., the latter is an indication that the technology area is well-developed and the innovation is more likely to be derivative and less valuable). Both of these findings indicate that valuable patents are more likely to be involved in litigation.

There are also large differences across different types of patent owners. Table 4 summarizes the mean filing and settlement rates for four ownership categories: individuals, domestic unlisted and listed companies, and foreign companies. Domestic listed companies are far less likely to file suits on their patents than unlisted companies and

reported).

\footnotetext{
${ }^{13}$ The percentages for the individual technology fields are: Drugs 0.25, Other Health 0.36, Chemicals 0.20, Electronics 0.37, Mechanical 0.20, Computers 0.34, Biotechnology 0.46, and Miscellaneous 0.15.
} 
individuals: their mean filing rate is 10.4 suits per thousand patents, as compared to 35- 45 suits for the smaller owners. Moreover, filing rates for foreign patentees (mostly unlisted firms) are much lower than for their domestic counterparts. These differences in mean filing rates are statistically significant, and the joint null hypothesis that they are the same is decisively rejected $\left(\chi^{2}(3)=11,853\right.$; p-value $\left.<.001\right)$.

Although filing rates differ sharply across ownership types, we find that ownership does not affect the probability that a suit is settled before it reaches the end of trial - which we call post-suit settlement. The formal $\chi^{2}(3)$ test statistic is 4.55 (p-value $\approx$ 0.2). Overall, about 95 percent of all patent suits filed are settled by the parties before the conclusion of trial (and most of those before the trial begins). But the systematic sorting on the ownership dimension occurs before suits are filed, not afterwards.

One explanation for why listed and unlisted firms have such different filing rates may be that the listed firms are typically larger and there may be advantages to size. As discussed above, there are two distinct aspects to such advantages. First, firms with larger patent portfolios may be better able to settle disputes through trading intellectual property, without resorting to suits (the portfolio size effect). Second, if imperfect capital markets constrain the ability of smaller firms to finance litigation, relatively large firms may be better able to settle because they pose greater litigation threats when confronting smaller firms. And when large firms have disputes with each other, they are likely to have many points of interaction other than trading intellectual property, especially through competition in product markets. This expectation of repeated interaction in other dimensions should promote settlement. We call these latter two aspects firm size effects. The detailed patent data will enable us to discriminate between the portfolio size and each firm size effect on litigation.

We begin by examining how the probability of litigation (i.e., of being involved in at least one suit over the life of the patent) and the probability of post-suit settlement varies with different portfolio sizes. To compute these probabilities, we adjust for the fact that patents from large portfolios are disproportionately represented in the matched data (since the matching was not stratified by portfolio size - see Appendix 2 for details). Table 5 shows that the probability of litigation sharply declines with portfolio size. A formal test confirms this finding $\left(\chi^{2}(6)=2,610\right.$; p-value <.001). The probability of filing a suit involving a patent in a portfolio with a small number of other patents (0-10) is 1.7 percent, compared to about 0.5 percent for a patent in a portfolio with 100-300 other patents, and only 0.25 percent for those in large portfolios ( $>900$ patents). These 
are large differences, and they show that having bigger portfolios confer substantial advantages in settling patent disputes without filing suits. But again, we observe only small differences in the post-suit settlement rates across portfolio size. The differences in point estimates are marginally statistically significant $\left(\chi^{2}(6)=14.2\right.$, p-value $\left.\approx 0.05\right)$.

To distinguish between the advantages of portfolio size and firm size, we divide domestic listed firms into two groups - those with employment around 1989 above the median level of 5,463 ("large") and those below the median ("small"). ${ }^{14}$ Panel A in Table 6 presents the litigation probability broken down both by portfolio size and this measure of company size. First, we see a fall in litigation probability with portfolio size within each ownership type, at least in point estimate. However, it is by far more precipious for domestic unlisted companies. For a patent owned by such a company and in a portfolio of $0-10$ other patents, the average probability of being involved in litigation is 2.6 percent, while for patents in the same sized portfolio but owned by listed domestic companies it is closer to one percent. At the same time, there is little evidence that size - either in terms of public listing or employment - matters once more than about 100 patents are held. For any given portfolio size, foreign companies are much less likely to file suits than other types of firms. The relationship between probability of litigation and portfolio size holds in each of the technology fields (not reported).

Similar to the results in Table 2, the probability of litigation differs substantially across technology areas, for any given ownership type. Here we also see, however, that the pattern of differences across fields depends on the type of owner (see Table 7).

One explanation for these differences in litigation probabilities is that firms with larger portfolios may have a higher propensity to patent their innovations, and thus more often have patents that are not worth fighting over. But the evidence contradicts this hypothesis. Portfolio size is positively, and significantly, correlated with forward citations and forward citations per claim - the correlation coefficients are 0.10 and 0.06 , respectively (these are computed using the matched sample and cohorts 1978-1988 to avoid spurious correlation due to both portfolio size and citations being truncated.) This indicates that the link between litigation probability and portfolio size does actually reflect the advantages that large portfolios give to firms in settling disputes.

But this is only half the story. Panel B in Table 6 presents the average probability

\footnotetext{
${ }^{14}$ Employment data are missing for 38 percent of our listed firms, either because their 1989 CUSIP does not match to a 2000 CUSIP or because their employment is not recorded. This group is not included for this test.
} 
of settlement for different portfolio sizes and ownership categories, conditional on a suit being filed. Here we see that post-suit settlement rates do not vary significantly with portfolio size, or with ownership type controlling for portfolio size.

In short, the likelihood of filing a suit (i.e., of not settling beforehand) is much higher for patents owned by individuals and unlisted companies, and for patentees with smaller patent portfolios to trade. But these differences do not appear in post-suit settlement rates. Thus, almost all of the sorting among disputes, on the basis of observed characteristics of patents and patentees, occurs before suits are filed, not afterwards in the courts.

To this point we have focused on the probability of litigation and of post-suit settlement. We now turn to the timing of such settlements and the win rates for cases that reach the trial adjudication stage. Table 8 summarises this information broken down by ownership type - domestic listed, domestic unlisted, and foreign firms, and all individuals. About 80 percent of all suits that are ever settled (without third party adjudication) are settled before a pre-trial hearing is held. This suggests that the filing of a suit sends a strong signal about the seriousness of the plaintiff to use legal means, and quickly triggers resolution before substantial legal costs are incurred. ${ }^{15}$ Nearly all of the remaining settlement occurs before the trial commences. However, the table shows that the timing of settlements differs little by ownership type.

The table also shows the trial win rates (for infringement suits). For domestic listed and unlisted firms, the win rates are very close to 50 percent, as predicted by the divergent expectations model of litigation. They are sharply inconsistent with the win rates of either zero or 100 percent predicted by the asymmetric information models. The point estimate of the win rate for foreign corporate patentees is only 42.7 percent, but the standard error is relatively large.

\section{Econometric Analysis}

In this section we present estimates of probit regressions on the determinants of the probability of infringement suits and post-suit settlement for the pooled data. These endogenous variables are related to the following regressors: the number of claims, forward citations per claim, backward citations per claim, the percentage of backward and for-

\footnotetext{
${ }^{15}$ Pooling all cases, the median number of months that pass before settlement occurs are 8,16 , and 25 for those settling before pre-trial hearing, after a hearing but before trial, and after trial, respectively.
} 
ward citations which are self-citations as measures of cumulative technology, the number of 3-digit USPC's as a measure of patent breadth, the size of the patent portfolio and the relative size of the patent portfolio, the latter as a measure of asymmetry between a patent owner and likely disputants, the technology concentration index, and ownership dummy variables that distinguish between patentees who are foreign or domestic individuals, unlisted or listed firms. The effects of technology and cohort on litigation probabilities are largely controlled by the matching, but because the litigated and matched data contain somewhat different numbers of patents, we also include technology group dummies.

We use the Derwent data as the basis for the sample, since it contains the link to patent numbers, and then include only those cases that can also be linked into the FJC database which contains the outcomes information. This procedure yields 6,538 litigated main patents. In analysing the determinants of the litigation probability (filing of suits), we do not count multiple cases involving the same patent. We do this to avoid undue influence by a few patentees suing many infringers in separate but related cases. We include multiple cases in the econometric analysis of the suit outcomes for three reasons: 1. this is appropriate if the purpose is to assess litigation risk for pricing patent insurance, 2. it is unclear how one would choose the "representative" suit when there are multiple cases, and 3. the sample size for outcomes (especially trials) is relatively small even when we include multiple cases.

Panel A in Table 9 summarises the parameter estimates and the sample marginal effect of each variable on the probability of litigation for a randomly drawn patent in the matched sample (i.e., at matched sample means). This is done separately for patent infringement and declaratory judgement suits. Since the sample litigation rate is close to 40 percent by construction, we must multiply the reported marginal effects by a conversion factor in order to obtain the marginal effects for a randomly drawn patent in the population (the conversion factors are given at the bottom of Table 9; see Appendix 3 for computational details). The statistical significance of variables and the relative size of their effects are preserved through this conversion, although magnitudes will depend on the specific population of interest. We focus the discussion on the results for patent infringement cases. Since the pattern of results is similar for declaratory judgement suits (Panel B), we do not discuss them in detail.

The probability of litigation increases with the number of claims and forward citations per claim, at a declining rate, and the effects are substantial. Evaluated at 
population means (litigation probability of 1.35 percent), a ten percent increase in the number of claims (1.2 claims at the mean) implies an increase of 3.1 percent in the population probability of litigation. It is noteworthy that the point estimate of the elasticity of the litigation probability with respect to claims is considerably smaller than unity. A unit elasticity is required to make it rational, on actuarial grounds, to price patent litigation insurance on a per claim basis, which is the standard procedure in policies currently available in the marketplace. We also find that a 10 percent increase in the number of forward citations per claim raises the probability of an infringement suit by 1.8 percent. These findings confirm the importance of the value of a patent in determining infringement suits. In related work on the determinants of re-examinations at the U.S. PTO and opposition proceedings at the European Patent Office - both events suggesting that the use of a patent is subject to dispute - Graham, et. al., (2001) and Harhoff and Reitzig (2000) find similar positive relationships.

The likelihood of an infringement suit falls with the number of backward citations per claim (at a declining rate). At mean values, a ten percent increase in the number of backward citations per claim reduces the litigation probability by 0.7 percent. While the effect is small, this finding is consistent with the view that backward citations are an indication that the patent is in a relatively well-developed technology area (where many related patents have been taken out) where uncertainties about property rights is less likely to cause frequent patent disputes (Lanjouw and Schankerman, 2001).

We have also argued that forward self-citations to a patent (given its total number of forward citations) indicates the presence of "cumulative innovation" by the patentee. That is, the patent owner is engaged in subsequent inventions that build on this earlier patent and that, as a result, he has a greater incentive to protect his property rights in this area. This hypothesis is supported by the positive and significant coefficient on the variable FWDSELF, the percentage of citations which is self-citation. At the mean $($ FWDSELF $=0.065)$, increasing the percentage of forward self-cites by 10 percent would raise the probability of an infringement suit by 0.4 percent (the estimate is proportionately higher for larger values of self-citing). At the same time, we find that greater backward self-citation (BWDSELF) significantly reduces the likelihood of litigation, but the effect is again small at the mean: raising the percentage of backward self-cites by ten percent lowers the litigation probability by about 0.25 percent. Greater backward self-citation in a patent indicates that an invention builds more extensively on one's own past research and is thus more likely to be a "derivative" invention. This evidence sup- 
ports the idea that there is complementarity among technologically-related inventions in a firm's R\&D portfolio, and that this raises the willingness to protect the property rights of the key, early inventions in the chain.

In our earlier work, we found that greater technological similarity of forward citations increased the probability of litigation. ${ }^{16}$ The similarity measure was used as an index of whether the technology area was "crowded" and thus more likely to generate potential disputes. However, we do not find any evidence of that link in the current, expanded data set.

Lerner (1994) suggests that patents with uses in many technological areas - "broad" patents - are more likely to be litigated because they face more potential infringers. Using the number of technology class assignments as a measure of patent breadth, he confirmed the hypothesis on a sample of biotechnology patents. Using more comprehensive data for various technology fields, Lanjouw and Schankerman (2001) found that broader patents are less likely to be involved in suits, but the evidence was weak. We test this hypothesis on our expanded and more recent data set, using the number of 3-digit USPC classes as the measure of breadth (NO3USPC). The estimated coefficient is similar to the earlier estimate by Lanjouw and Schankerman and highly significant. A ten percent increase in NO3USPC (the mean number of technology field assignments is 2.2) reduces the litigation probability by about 1.7 percent. ${ }^{17}$ This finding suggests that it is harder to detect infringements when the patented innovation is used in more technology areas, and that this effect dominates any increase in the number of potential infringers associated with greater patent breadth.

An important finding is that the probability of litigation is negatively related to the size of the patent portfolio, with an elasticity (at the mean) of -0.13 . The marginal effect of portfolio size declines with larger portfolios (positive quadratic term), but the point estimate of the portfolio effect is negative over most of the sample range. This means that having a larger portfolio of patents reduces the probability of being involved in a suit on any individual patent owned by the firm - i.e., there are beneficial "enforcement spillovers" across patents within a given firm. We can compute by how much increasing

\footnotetext{
${ }^{16}$ Similarity measures whether subsequent citing patents fall in similar technology fields as the patent in question. It is calculated by finding the percentage of 3-digit USPC assignments of each citing patent that overlap with those of the patent itself, and averaging over all citing patents.

${ }^{17}$ The point estimates in the separate technology fields (not reported) are negative and statistically significant in five cases, negative but insignificant in two, and positive but insignificant in one.
} 
portfolio size reduces the litigation probability of any constituent patent. For example, raising the portfolio from 100 to 500 patents lowers the litigation probability on an "average" patent (with characteristics at their mean values) by 0.13 percentage points, or about 10 percent of the mean probability. Going from a portfolio of 500 to 2500 reduces the probability by 0.21 percentage points, or by about 15 percent. Harhoff and Reitzig (2000) find that larger portfolios also tend to keep owners out of European opposition proceedings.

The impact of portfolio size on the probability of litigation is smaller for drug patents than for patents in other technology fields. Estimation at the technology field level (not reported) suggested this hypothesis (the other differences in the estimated portfolio coefficients across technology fields were not statistically significant). To test the hypothesis, we include a portfolio dummy variable for non-drug technology fields (PortNondrug). The estimated coefficient is negative and large relative to the baseline portfolio effect. Using the estimated coefficients on Portsize and PortNondrug, we find that the marginal effect of portfolio size on the litigation probability is nearly twice as large for non-drug patents as compared to drug patents. This finding is consistent with the idea that trading intellectual property is especially important in areas where innovation is "complex" in the sense that it may rely on multiple components or research tools that may be patented by other firms. This feature has been less important in drugs. Somaya (2001) finds a similar difference using a somewhat overlapping technology definitions and a related variable for portfolio size. He finds that the size of a patentee's portfolio has an insignficant effect on the litigation of patents for research medicine while it has a negative effect for computer patents.

The portfolio effect captures the ability of firms to trade patents as a means of settling disputes. Smaller companies may have few alternative mechanisms to facilitate settlement, so we expect portfolio size to be more important for smaller firms. To test this hypothesis, we include interaction effects between portfolio size and ownership type (unlisted, small domestic and foreign listed, with large domestic listed firms the left out category). The point estimates strongly support the hypothesis that company size affects the importance of having larger patent portfolios. For a small domestic listed company with the mean portfolio size (1,420 patents), the marginal effect of portfolio size on the probability of litigation is about eight times larger than for a large listed company with the same portfolio (compare marginal effects for Portsize and PortDLIST-S). The marginal effect of portfolio size for small listed firms is even greater than that for unlisted 
firms. In short, what is important for settlement is that firms either have a portfolio of intellectual property to trade, or have other dimensions of interaction that promote "cooperative" behavior.

Additional evidence that the expectation of repeated interaction promotes settlement is provided by the technology concentration variable $(C 4)$, defined in Section 3 . If a company operates in concentrated technology areas (i.e., where the top four firms account for a larger share of patenting), there is a greater chance the company will be involved in repeated patent disputes with the same firms. This should increase the likelihood of settlement and thus reduce the probability of litigation. As predicted, the coefficient on the technology concentration index is negative and highly significant, and the quantitative effect on the litigation probability is large. A ten percent increase in the four-firm technology concentration index reduces the probability of a suit by 4.6 percent.

The portfolio size, company size and technology concentration variables capture the ability to trade and the role of repeated interaction. We also find that the litigation probability is influenced by the asymmetry in portfolio size between the patent owner and likely disputants, which we interpret as reflecting relative threat power of the parties. The coefficient on the relative size variable (Relsize) is significantly negative for infringement suits, as expected. ${ }^{18}$ If a patent owner is large relative to typical disputants, the probability of litigation is lower (settlement is more likely). However, the effect is not very large - a ten percent increase in relative size lowers the litigation probability by 0.5 percent. Interestingly, relative size does not matter in declaratory judgment suits, those where the patent owner is the defendant (Panel B). The prediction was that larger relative size (of the patentee) would make settlement more difficult or have no effect for declaratory judgement suits, and we find the latter.

We easily reject the hypothesis that there are no ownership differences, when we control for other factors $\left(\chi^{2}(6)=978.8\right.$, p-value $\left.<0.001\right)$. The pattern of marginal effects on the ownership dummies points to five main findings about the conditional effects of ownership type on the propensity to litigate. First, foreign individuals and unlisted (smaller) companies are much less likely to engage in infringement suits than their domestic counterparts. Comparing the marginal effects of FIND and DIND, we see that the probability of litigation is much lower - by about 1.2 percentage points - for foreign

\footnotetext{
${ }^{18}$ Two points should be noted. For patents without any forward citations, the denominator in the RelSize variable is set equal to the average portfolio size for other patents in the same 2-digit USPC class as the patent in question. For all individuals, and for about 900 cases where company patentees had only one patent, we set RelSize equal to zero.
} 
individual owners than for their domestic counterparts. Comparing foreign and domestic unlisted companies (FUNLIST and DUNLIST), the difference is even larger, about 2.0 percentage points. Second, larger domestic and foreign listed companies are equally likely to file suits. Third, domestic individuals, unlisted and small listed companies are equally likely to litigate (the differences in point estimates are not statistically significant). Fourth, domestic individuals and unlisted companies are more likely - by about 0.9 percentage points - to litigate than large domestic listed firms. And finally, small listed companies are far more likely to file suits than larger ones, the difference being about 1.0 percentage points on average.

To summarise, we find the following ranking of the propensity to litigate, where DLISTS and DLISTB are small and large (or unclassified) listed, domestic firms, respectively: $D L I S T S=D U N L I S T=D I N D>D L I S T B=F L I S T>F I N D=$ FUNLIST. Since these effects are conditional on portfolio and company size (both of which relate to the cost of settling), this ranking should reflect two main factors: the cost of litigation and access to information about potential infringements. We expect that the cost of litigating for domestic patentees is less than (or equal to) that for foreign patentees, and that it is harder for foreign owners to detect infringements in the U.S. Given the cost of settling disputes, these hypotheses predict that domestic owners should litigate more often than their foreign counterparts. That is what we find, except for listed companies. This exception is not surprising, since foreign firms that are listed, and with a presence, in the U.S. are less likely to be at much disadvantage in terms of litigation costs and access to information.

Table 10 highlights the enormous heterogeneity in litigation risk implied by these estimation results. We calculate the population probability of involvement in an infringment suit for each patent in the matched sample, given the patent's full set of characteristics. The 50th-99th percentile cutoffs for the distribution of these probabilities is given in the first row of the table. The probability of litigation for the median patent is just under one percent. However, among the top one percent of patents (99th percentile), the probability of involvement in a suit is over eight percent. The table shows that the rates can be far higher when the patents are segregated into different technology and ownership groups. The top percentile of patents in areas that are most at risk have probabilities of litigation over 15 percent (see Other Health, Computers and Biotechnology). Similarly, the top one percent of all patents held by domestic unlisted firms or individuals have a litigation risk over 10 percent. Since most evidence, 
from patent renewal data and firm surveys, indicates that private value of innovations is highly skewed - with most value attributable to the top patents - it is precisely the litigation risk in these top percentiles that is relevant for determining incentives.

We now turn to the econometric analysis of post-suit outcomes. In estimating these regressions, we do not control for selection - i.e., we do not use a (filing) selection equation together with the outcomes equation. Selection bias arises if there is significant covariance between the disturbances in the filing and outcome equations. We ask: given the selection that occurs at filing, is there any remaining association between patent and patentee characteristics and the outcomes? For purposes of assessing ex ante litigation risk (e.g., for patenting decisions or insurance pricing), this is the relevant question. Controlling for selection in the analysis of outcomes (e.g., Somaya, 2001) is appropriate if one wanted to infer the effects of characteristics in a random sample at the outcomes stage. In any event, the evidence that there is any sample selection bias is mixed (Somaya 2001).

The non-parametric evidence presented in the previous section indicated that the main characteristics of patents and their owners do not affect the probability of settlement after a suit is filed, nor the plaintiff win rates for cases that reach trial. The probit regressions for settlement and win rates confirm this conclusion. For brevity we summarise the findings but do not present the parameter estimates. The settlement regression has a meager pseudo- $R^{2}$ of 0.01 . The null hypothesis that the regression as a whole is insignificant is not rejected $\left(\chi^{2}(29)=39.7, \mathrm{p}\right.$-value $\left.=0.089\right)$. The only positive finding is that the coefficients on three technology field dummies are significant and indicate that the settlement probability is about eight percentage points higher for patents in Electronics, Mechanical and Miscellaneous. ${ }^{19}$ The probit regression for win rates has a pseudo- $R^{2}$ of 0.02 . The whole regression is statistically insignificant $\left(\chi^{2}(28)=19.7\right.$, pvalue $=0.90)$, as is each individual coefficient. Based on our discussions with staff at the Federal Judicial Center, there is no reason to believe that the data on settlements and plaintiff win rates are systematically bad (these outcome data are recorded at different times and in many different courts). We are confident that the "insignificance" of these

\footnotetext{
${ }^{19} \mathrm{It}$ is also interesting to note that, if we restrict attention to suits where the original patentee is identified as the plaintiff, then those suits involving smaller patentees (unlisted firms and domestic individuals) are significantly less likely to settle. These are patentees who do not have an exclusive licensee or late assignee litigating in their place. As plaintiffs they are more likely to be inexperienced and more attached to their innovations than owners who have licensed or sold out. Both characteristics could impede settlement.
} 
regressions is meaningful: i.e., settlement and win rate outcomes are almost completely independent of observed characteristics of patents and their owners.

The probability that the settlement of infringement suits occurs early (before the pre-trial hearing) is also unrelated to most characteristics of the patent and its owner, with three noteworthy exceptions (the probit regression is significant: $\chi^{2}(29)=50.5$, $\mathrm{p}$-value $=0.008)$. First, early settlement is more likely if the patent in dispute is part of a larger portfolio (Portsize). A one standard deviation increase in portfolio size (1,300 patents) raises the probability of early settlement by about 12.9 percent. This is consistent with our earlier result that portfolio size makes filing a suit less likely in the first place, due to greater ability to "trade" intellectual property. Second, a higher technology concentration index $(C 4)$ makes early settlement somewhat less likely. A one standard deviation increase (doubling) in the concentration index lowers the probability by about two percent. Finally, patent owners that are large relative to a representative disputant (Relsize) are also less likely to settle early. A one standard deviation rise in relative size reduces the probability of early settlement by about five percent. ${ }^{20}$ Recall that the probability that a suit is filed is lower when the relative size of the patentee is larger, which we interpret as reflecting greater threat power. But if the (implicit) threats do not succeed in preventing the need to file suit, it is important for the patentee to carry out those threats in order to maintain credibility (post-suit "toughness"). Similarly, it the discipline of repeated interaction has failed to keep firms in a concentrated area out of court in the first place, the dispute is probably very intractable. Both could delay any post-suit settlement, and this is what we find.

\section{Concluding Remarks}

We study the determinants of patent infringement and declaratory judgement suits, and their outcomes, by linking detailed information from the U.S. patent office to data from the U.S. federal court system, the Derwent database and industry sources. This allows us to construct a suitable controlled random sample of the population of potential disputants. The data set we construct is the most comprehensive yet available, covering all patent suits in the U.S. reported by the federal courts during the period 1978-1999.

A major finding in the paper is that all of the sorting among patent disputes on

\footnotetext{
${ }^{20}$ Marginal changes are given in terms of standard deviations here because the distribution of these variables is very skewed after the selection for filing.
} 
observable characteristics occurs in the decision to file suits. The key post-suit outcomes - the probability of settlement and plaintiff win rates at trial - do not depend on these characteristics. From a policy perspective, this is good news because it means that enforcement of patent rights relies on the effective threat of court action (suits) more than on extensive post-suit, legal proceedings that consume court resources. This feature is reinforced by high post-suit settlement rates and the fact that most settlement occurs soon after the suit is filed, often before the pre-trial hearing is held. These findings mean that the enforcement of patent rights minimises the use of judicial resources for sorting out patent disputes. The bad news is that individuals and small companies are much more likely to be involved in suits, conditional on the characteristics of their patent, but they are no more likely to resolve disputes quickly in post-suit settlements. We provide clear evidence that what is important for settlement is that firms either have a portfolio of intellectual property to trade, or have other dimensions of interaction that promote "cooperative" behavior. In this sense, small firms are at some disadvantage in the their attempts to protect their intellectual property. But the fact that the heterogeneity in litigation risk is measurable offers the prospect of developing a market for effective, and affordable, patent litigation insurance.

An important direction for future research is to explore the dynamic aspects of conflict between firms over intellectual property assets. This would include studying the determinants of the filing and outcomes of multiple (sequential) suits on the same patent with different parties, and multiple suits on different patents involving the same parties. Initial work along these lines for a sample of cases is found in Somaya (2001). Proceeding further requires matching the names of litigants across all cases, a project underway. When completed these data will provide information about the role of reputation building in the area of patent enforcement and allow a more detailed assessment of litigation risk and its associated costs. Even without this information, however, the findings in this paper can and should be exploited to develop economically rational pricing of litigation risk in insurance markets, and theoretical work may be useful in understanding how effective litigation insurance markets are likely to affect strategic interaction and R\&D incentives among different firms. 


\section{Appendix 1. Reporting and Truncation Rates for Case Filings (percent)}

$\begin{array}{llll}\text { Cohort } & \text { Reporting } & \text { Lag } & \text { Truncation } \\ 1978 & 15.9 & 1 & 97.6 \\ 1979 & 25.0 & 2 & 91.3 \\ 1980 & 26.6 & 3 & 82.4 \\ 1981 & 30.2 & 4 & 75.3 \\ 1982 & 29.4 & 5 & 67.8 \\ 1983 & 33.9 & 6 & 60.2 \\ 1984 & 36.8 & 7 & 52.8 \\ 1985 & 33.7 & 8 & 44.9 \\ 1986 & 38.7 & 9 & 37.7 \\ 1987 & 43.0 & 10 & 30.0 \\ 1988 & 48.5 & 11 & 23.7 \\ 1989 & 49.5 & 12 & 18.1 \\ 1990 & 61.2 & 13 & 12.5 \\ 1991 & 60.0 & 14 & 7.2 \\ 1992 & 57.6 & 15 & 3.7 \\ 1993 & 50.0 & 16 & 1.2 \\ 1994 & 54.4 & 17 & 0.2 \\ 1995 & 53.6 & 18 & 0.0 \\ 1996 & 55.2 & & \end{array}$

Notes: The reporting rate is computed as the number of cases reported in Derwent divided by the number in the Federal Judicial Center data. The truncation rate is computed from the lag structure of filings for cohorts 1982-1986. The reporting rate for 1996 is used for 1997-1999, as data are not available. 


\section{Appendix 2. Computing Population Filing Probabilities and their Variance}

Let $L_{z, g}, M_{z, g}$ and $N_{z, g}$ denote, respectively, the number of patents in the litigated and matched samples and in the population that are in portfolios of size $z$ and from group $g$, where the latter is defined by technology field, cohort, and ownership type. The observed filing probabilities in the sample are $L_{z, g} /\left(L_{z, g}+M_{z, g}\right)$. The filing probabilities in the population are $q_{z, g}=\frac{L_{z, g}}{N_{z, g}}$. We cannot calculate these directly as $N_{z, g}$ is unobserved. However, since the matched sample is random with respect to portfolio size, we can use the sample share of the patents in group $g$ that are in portfolios of size $z, \widehat{s_{z, g}}=\frac{M_{z, g}}{M_{g}}$, as an unbiased estimator of the population share $\frac{N_{z, g}}{N_{g}}$. Using this, our estimator is:

$$
\widehat{q_{z, g}}=\frac{L_{z, g}}{N_{g}} \frac{1}{\widehat{s_{z, g}}}
$$

Now, treating the population itself as a sample from an underlying distribution, $\frac{L_{z, g}}{N_{g}}$ will also be an estimate of an underlying probability, say $p$, with an associated sampling variance. Taking a Taylor expansion, we can capture both sources of error in the following approximation:

$$
\operatorname{Var}\left(\widehat{q_{z, g}}\right) \equiv \operatorname{Var}\left(\widehat{p} \frac{1}{\widehat{s_{z, g}}}\right) \approx\left[\frac{-\widehat{p}}{{\widehat{s_{z, g}}}^{2}}\right]^{2} \frac{\widehat{s_{z, g}}\left(1-\widehat{s_{z, g}}\right)}{M_{g}}+\left[\frac{1}{\widehat{s_{z, g}}}\right]^{2} \frac{\widehat{p}(1-\widehat{p})}{N_{g}}
$$

where the covariance terms are zero because the two sources of sampling error are independent. This simplifies to:

$$
\operatorname{Var}\left(\widehat{q_{z, g}}\right) \approx \widehat{q_{z, g}} 2\left[\frac{\left(1-\widehat{s_{z, g}}\right)}{m_{z, g}}\right]+\frac{\widehat{q_{z, g}}}{N_{g}}\left[\frac{1}{\widehat{s_{z, g}}}-\widehat{q_{z, g}}\right]
$$

Filing probabilities at a more aggregated level are calculated as a weighted average of these rates, with weights based on $M_{g}$. 


\section{Appendix 3. Deriving Population Litigation Probabilities and Marginal Effects}

\section{Population Litigation Probabilities}

We define classes by using characteristics with respect to which the sampling was non-random: USPC groups, cohort, infringement suits, and declaratory judgement suits. Let $P\left(X_{c}\right)$ denote the population probability of litigation for a patent in class $c$ with a vector of other characteristics $X_{c}$ and let $Q\left(X_{c}\right)$ be the corresponding probability in the pooled (litigated and matched) sample. $P\left(X_{c}\right)$ and $Q\left(X_{c}\right)$ differ because the matched sample was constructed so that the overall litigation probability is fifty percent, controlling for technology and cohort. We want to infer $P\left(X_{c}\right)$ from the estimated value of $Q\left(X_{c}\right)$.

First we determine the extent to which we must inflate the matched sample for a given class to have it reflect the number of unlitigated patents in that class in the population. Let $Q$ and $P$ represent the aggregate sample and population litigation probabilities for a given class:

$$
Q=L /(L+M)
$$

where $L$ and $M$ denote the number of litigated and matched patents in the sample. The population probability is

$$
P=L / N
$$

The number of litigated patents is the same in both cases since the sample contains all (reported) litigated patents, and $N$ is the number of unlitigated patents in the class in the population. Using these equations, we get

$$
N=\{Q /(1-Q) P\} M \equiv K M
$$

Within a class, the matched patents are random draws so the distribution of characteristics in the matched sample is the same as the population. Thus the expected number of matched patents with characteristics $X_{c}$ in the population, $N\left(X_{c}\right)$, is greater than in the sample by the inflation factor, $K$, and so equals $K M\left(X_{c}\right)$. Letting $L\left(X_{c}\right)$ be the number of litigated patents with characteristics $X_{c}$, the expected population probability of litigation for such patents is

$$
P\left(X_{c}\right)=L\left(X_{c}\right) /\left[K M\left(X_{c}\right)\right]
$$


Similarly, $Q\left(X_{c}\right)=L\left(X_{c}\right) /\left[L\left(X_{c}\right)+M\left(X_{c}\right)\right]$. Solving for $M$ and substituting we get the result:

$$
P\left(X_{c}\right)=Q\left(X_{c}\right) /\left[K\left(1-Q\left(X_{c}\right)\right)\right]
$$

Population Marginal Effects

For each characteristic $X_{k}$, the population marginal effect is

$$
\partial P\left(X_{c}\right) / \partial X_{k c}=\left[d P\left(X_{c}\right) / d Q\left(X_{c}\right)\right] \partial Q\left(X_{c}\right) / \partial X_{k c}
$$

The last term is the sample marginal effect computed from the probit regression. From the expression for $P\left(X_{c}\right)$ we get

$$
d P\left(X_{c}\right) / d Q\left(X_{c}\right)=1 / K\left[1-Q\left(X_{c}\right)\right]^{2}
$$

Measuring $Q\left(X_{c}\right)$ by the sample probability of litigation in the class, $Q$, we get the result:

$$
d P\left(X_{c}\right) / d Q\left(X_{c}\right) \simeq P / Q(1-Q) .
$$

We measure $P$ for each class as follows: For the denominator, we take the total number of patents in the class during 1978-1995. In the numerator we use the number of infringement or declaratory judgement suits that can be directly identified as such and include all others as infringement suits. These are inflated for underreporting and for truncation as described in Appendix 1. We then calculate marginal adjustment factors by USPC groups, infringement and declaratory judgement suits. Separate classes defined by cohort are not needed because of the maintained hypothesis that the litigation model applies to all cohorts, making non-systematic sampling in this dimension unimportant. Results are at the bottom of Table 9. Because $d P\left(X_{c}\right) / d Q\left(X_{c}\right)$ is the same for all $X_{k}$ for a given class $c$, all sample marginal effects are adjusted by the same factor to convert them to population marginals. 
Table 1. Composition of Sample: All Filed Cases, Cohorts 1978-95

$\begin{array}{lrr}\quad \text { Technology } & \text { Number } & \text { Percent } \\ \text { Drugs } & 573 & 5.6 \\ \text { Other Health } & 825 & 8.0 \\ \text { Chemical } & 1,378 & 13.4 \\ \text { Electronics } & 1,924 & 18.7 \\ \text { Mechanical } & 2,848 & 27.7 \\ \text { Computers } & 183 & 1.8 \\ \text { Biotechnology } & 92 & 0.9 \\ \text { Miscellaneous } & 2,456 & 23.9 \\ & & \\ \text { TOTAL } & 10,279 & 100.0\end{array}$


Table 2. Filing Rates, by Technology Field and Cohort Groups Filing Rate (cases per thousand) Total: $1978-95 \quad 1978-84 \quad 1985-90 \quad 1991-95$ Technology Field

$\begin{array}{ccccc}\text { Aggregate } & \mathbf{1 9 . 0} & \mathbf{1 9 . 3} & \mathbf{1 6 . 6} & \mathbf{2 1 . 1} \\ & (0.21) & (0.31) & (0.28) & (0.44) \\ \text { Drugs } & & & & \\ & \mathbf{2 2 . 2} & \mathbf{2 2 . 5} & \mathbf{1 8 . 9} & \mathbf{2 4 . 3} \\ & (1.05) & (1.62) & (1.34) & (1.97) \\ \text { Other Health } & \mathbf{3 4 . 6} & \mathbf{4 8 . 2} & \mathbf{3 5 . 2} & \mathbf{2 7 . 3} \\ & (1.33) & (2.67) & (1.98) & (2.23) \\ \text { Chemicals } & & & & \\ & (0.35) & (0.50) & (0.49) & (0.80) \\ \text { Electronics } & \mathbf{1 1 . 8} & \mathbf{1 1 . 6} & \mathbf{1 0 . 9} & \mathbf{1 3 . 0} \\ & (0.40) & (0.61) & (0.51) & (0.79) \\ \text { Mechanical } & \mathbf{1 5 . 4} & \mathbf{1 6 . 2} & \mathbf{1 3 . 1} & \mathbf{1 6 . 8} \\ & (0.2) & (0.53) & (0.46) & (0.79) \\ \text { Computers } & & & & \\ & \mathbf{1 6 . 9} & \mathbf{1 7 . 7} & \mathbf{1 4 . 5} & \mathbf{1 8 . 7} \\ & (2.25) & (4.24) & (2.80) & (3.78) \\ \text { Biotechnology } & & & & \\ & \mathbf{2 7 . 9} & \mathbf{3 3 . 3} & \mathbf{2 7 . 6} & \mathbf{2 5 . 5} \\ & (3.36) & (6.13) & (5.16) & (5.52) \\ \text { Miscellaneous } & & & & \\ & \mathbf{3 4 . 2} & \mathbf{3 2 . 4} & \mathbf{2 8 . 9} & \mathbf{4 0 . 7} \\ & (0.76) & (1.10) & (0.98) & (1.66)\end{array}$

Notes: The filing rates cover all patent suits filed through 1999, including multiple suits on the same patent. Figures are adjusted both for under-reporting and for truncation (based on the filing rate structure for cohorts 1982-1986). Numbers in bold are statistically significant at the 0.01 level. 
Table 3. Mean Citations and Claims per Patent, by Ownership Type

\begin{tabular}{ccccc} 
& \multicolumn{2}{c}{ Domestic Listed } & \multicolumn{2}{c}{ Domestic } \\
Mean & Filed Cases & Matched & Filed Cases & Matched \\
& & & & \\
Claims & $\mathbf{1 8 . 8}$ & $\mathbf{1 3 . 1}$ & $\mathbf{1 8 . 6}$ & $\mathbf{1 4 . 0}$ \\
& $(0.60)$ & $(0.25)$ & $(0.21)$ & $(0.23)$ \\
Forward cites/claim & $\mathbf{2 . 1 7}$ & $\mathbf{0 . 9 8}$ & $\mathbf{1 . 2 5}$ & $\mathbf{0 . 8 5}$ \\
& $(0.10)$ & $(0.02)$ & $(0.03)$ & $(0.04)$ \\
Backward cites/claim & $\mathbf{1 . 0 0}$ & $\mathbf{1 . 1 8}$ & $\mathbf{1 . 1 1}$ & $\mathbf{1 . 2 0}$ \\
& $(0.04)$ & $(0.02)$ & $(0.03)$ & $(0.04)$ \\
& & & & \\
Mean & Foreign Firms & & Individuals \\
Claims & Filed Cases & Matched & Filed Cases & Matched \\
& $\mathbf{1 4 . 5}$ & $\mathbf{1 0 . 6}$ & $\mathbf{1 4 . 2}$ & $\mathbf{1 1 . 0}$ \\
& $(0.38)$ & $(0.13)$ & $(0.19)$ & $(0.17)$ \\
Forward cites/claim & $\mathbf{1 . 5 8}$ & $\mathbf{0 . 7 6}$ & $\mathbf{1 . 5 7}$ & $\mathbf{0 . 8 4}$ \\
& $(0.07)$ & $(0.02)$ & $(0.04)$ & $(0.03)$ \\
Backward cites/claim & $\mathbf{0 . 9 5}$ & $\mathbf{0 . 9 9}$ & $\mathbf{1 . 0 9}$ & $\mathbf{1 . 3 4}$ \\
& $(0.03)$ & $(0.02)$ & $(0.02)$ & $(0.03)$
\end{tabular}

Notes: Citations include self-cites. Estimated standard errors are in parentheses. Numbers in bold are statistically significant at the 0.01 level. 
Table 4. Filing and Settlement Rates, by Ownership Type

\author{
Individuals Dom. Unlisted Dom Listed Foreign Firms
}

$\begin{array}{ccccc}\text { Filing Rate } & \mathbf{3 5 . 2} & \mathbf{4 6 . 0} & \mathbf{1 0 . 4} & \mathbf{4 . 2} \\ \text { (cases/thousand) } & (0.65) & (0.78) & (0.27) & (0.16) \\ & & & & \\ \begin{array}{c}\text { Settlement Rate } \\ \text { (percent) }\end{array} & \mathbf{9 4 . 7} & \mathbf{9 4 . 0} & \mathbf{9 4 . 1} & \mathbf{9 4 . 5} \\ & (1.4) & (0.4) & (0.7) & (0.9)\end{array}$

Notes: Foreign firms include both listed and unlisted companies. The filing rate is the number of suits filed per thousand patents, including multiple suits on the same patent, from cohorts 1978-1995 (as in Table 2). The settlement rate is the fraction of filed cases that are reported to have been settled at some time prior to court judgement, according to the FJC. Settlement rates are computed for suits filed during the period 1978-1992 to minimize truncation bias and include only infringement suits. Estimated standard errors in parentheses. Numbers in bold are statistically significant at the 0.01 level. 
Table 5. Probability of Litigation and Settlement, by Patent Portfolio Size

$\begin{array}{ccc}\text { Portfolio Size } & \begin{array}{c}\text { Prob. of Litigation } \\ \text { (percent) }\end{array} & \begin{array}{c}\text { Settlement Rate } \\ \text { (percent) }\end{array} \\ 0-10 & \mathbf{1 . 7 1}(0.05) & \mathbf{9 5 . 0}(0.5) \\ 11-100 & \mathbf{1 . 2 0}(0.05) & \mathbf{9 3 . 3}(0.7) \\ 101-200 & \mathbf{0 . 5 2}(0.05) & \mathbf{9 3 . 0}(1.7) \\ 201-300 & \mathbf{0 . 4 3}(0.06) & \mathbf{9 7 . 0}(1.3) \\ 301-600 & \mathbf{0 . 3 9}(0.04) & \mathbf{9 0 . 9}(1.9) \\ 601-900 & \mathbf{0 . 3 4}(0.04) & \mathbf{9 3 . 3}(2.5) \\ >900 & \mathbf{0 . 2 6}(0.01) & \mathbf{9 3 . 2}(1.1)\end{array}$

Notes: The probability of litigation is adjusted for underreporting and truncation and for the over-representation of patents from large portfolios (Appendix 2). See also notes to Table 4. 
Table 6. Probability of Litigation and Settlement, by Patent Portfolio Size and Ownership Type

Panel A. Probability of Litigation (percent)

Large Dom.Listed Small Dom. Listed Dom.Unlisted Foreign Firms

$\begin{array}{ccccc}\begin{array}{c}\text { Portfolio } \\ 0-10\end{array} & \mathbf{0 . 5 5}(.26) & \mathbf{1 . 0 9}(.49) & \mathbf{2 . 6 3}(.09) & \mathbf{0 . 4 8}(.03) \\ 11-100 & \mathbf{1 . 1 6}(.25) & \mathbf{1 . 7 8}(.32) & \mathbf{2 . 0 0}(.09) & \mathbf{0 . 3 7}(.03) \\ 101-200 & \mathbf{0 . 7 0}(.14) & \mathbf{0 . 7 7}(.28) & \mathbf{0 . 6 7}(.12) & \mathbf{0 . 2 3}(.03) \\ 201-300 & \mathbf{0 . 4 9}(.17) & \mathbf{0 . 8 2}(.32) & \mathbf{0 . 8 4}(.27) & \mathbf{0 . 1 8}(.04) \\ 301-600 & \mathbf{0 . 5 4}(.10) & \mathbf{0 . 7 0}(.31) & \mathbf{0 . 5 6}(.10) & \mathbf{0 . 1 9}(.03) \\ 601-900 & \mathbf{0 . 6 2}(.10) & \mathbf{0 . 4 4}(.25) & \mathbf{0 . 3 4}(.12) & \mathbf{0 . 1 8}(.04) \\ >900 & \mathbf{0 . 3 9}(.02) & \mathrm{nc} & \mathbf{0 . 3 7}(.06) & \mathbf{0 . 1 2}(.01)\end{array}$

Panel B. Settlement Rates (percent)

Dom. Listed Dom.Unlisted Foreign Firms

$\begin{array}{cccccc}\text { Portfolio } & & & & & \\ 0-10 & \mathbf{9 0 . 0} & (3.1) & \mathbf{9 5 . 0} & (0.5) & \mathbf{9 5 . 9}(1.3) \\ 11-100 & \mathbf{9 5 . 0}(1.3) & \mathbf{9 3 . 0}(0.9) & \mathbf{9 1 . 2}(2.3) \\ 101-200 & \mathbf{9 2 . 9} & (2.4) & \mathbf{9 2 . 1} & (3.4) & \mathbf{9 5 . 0}(3.4) \\ 201-300 & \mathbf{9 8 . 8} & (1.2) & \mathbf{9 7 . 9} & (2.1) & \mathbf{9 0 . 3}(5.3) \\ 301-600 & \mathbf{9 2 . 0}(2.4) & \mathbf{8 5 . 2} & (3.9) & \mathbf{1 0 0 . 0}(0.0) \\ 601-900 & \mathbf{9 6 . 3} & (2.6) & \mathbf{8 7 . 5} & (5.8) & \mathbf{9 4 . 4}(5.4) \\ >900 & \mathbf{9 4 . 1} & (1.3) & \mathbf{8 8 . 8} & (3.0) & \mathbf{9 5 . 3}(2.6)\end{array}$

Notes: The probability of litigation is the number of patents involved in suits (multiple suits not counted) per hundred patents, adjusted for underreporting and truncation and for the over-representation of patents from large portfolios (Appendix 2). 'nc' denotes an empty cell. See also notes to Table 4. 
Table 7. Probability of Litigation, by Technology and Firm Ownership (in percent)

\begin{tabular}{cccccc} 
& Dom. Unlisted & Small Dom. Listed & Large Dom. Listed & Foreign \\
Technology & & \multicolumn{1}{c}{ Sm } & & \\
Drugs & $\mathbf{9 . 1}(0.2)$ & $\mathbf{2 . 9}(0.2)$ & $\mathbf{4 . 2}(0.2)$ & $\mathbf{3 . 3}(0.1)$ \\
Other Health & $\mathbf{1 0 . 5}(0.2)$ & $\mathbf{9 . 1}(0.4)$ & $\mathbf{4 . 1}(0.3)$ & $\mathbf{2 . 2}(0.1)$ \\
Chemicals & $\mathbf{3 . 8}(0.1)$ & $\mathbf{3 . 9}(0.1)$ & $\mathbf{1 . 2}(0.05)$ & $\mathbf{0 . 5}(0.02)$ \\
Electronics & $\mathbf{6 . 6}(0.1)$ & $\mathbf{1 2 . 3}(0.1)$ & $\mathbf{1 1 . 2}(0.1)$ & $\mathbf{0 . 8}(0.02)$ \\
Mechanical & $\mathbf{6 . 8}(0.1)$ & $\mathbf{3 . 9}(0.1)$ & $\mathbf{1 1 . 2}(0.1)$ & $\mathbf{0 . 7}(0.02)$ \\
Computers & $\mathbf{1 4 . 9}(0.6)$ & nc & $\mathbf{1 . 3}(0.2)$ & $\mathbf{0 . 3}(0.06)$ \\
Biotechnology & $\mathbf{2 0 . 1}(0.7)$ & $\mathbf{3 . 9}(0.6)$ & $\mathbf{3 . 4}(0.6)$ & $\mathbf{7 . 2}(0.5)$ \\
Miscellaneous & $\mathbf{1 1 . 2}(0.2)$ & $\mathbf{4 . 2}(0.1)$ & $\mathbf{2 . 6}(0.1)$ & $\mathbf{1 . 3}(0.04)$
\end{tabular}

Notes: See notes to Table 5. 


\section{Table 8. Timing of Settlements and Trial Win Rates, by Ownership Type}

$\begin{array}{ccccc} & \text { Dom. Listed } & \text { Dom. Unlisted } & \text { Foreign Firms } & \text { Individuals } \\ \text { Timing of settlement (\%): } & & & & \\ \text { Before pre-trial hearing } & \mathbf{8 1 . 2} & \mathbf{8 3 . 0} & \mathbf{7 8 . 8} & \mathbf{8 4 . 7} \\ & (1.2) & (0.7) & (1.7) & (0.8) \\ \text { Before trial } & \mathbf{1 8 . 0} & \mathbf{1 5 . 5} & \mathbf{1 9 . 9} & \mathbf{1 4 . 2} \\ & (1.2) & (0.7) & (1.7) & (1.8) \\ \text { During trial } & \mathbf{0 . 8} & \mathbf{1 . 5} & \mathbf{1 . 3} & 1.1 \\ & (0.3) & (0.2) & (0.5) & (1.9) \\ \text { Plaintiff Win Rate at Trial } & \mathbf{5 1 . 2} & \mathbf{4 9 . 1} & \mathbf{4 2 . 7} & \mathbf{4 6 . 5} \\ & (3.8) & (2.3) & (4.9) & (2.3)\end{array}$

Notes: The timing of settlements is computed on the basis of all infringement cases filed during the period 1978-1992 and terminated by settlement before or during trial, according to the FJC. Cases that proceed beyond trial (e.g., on appeal or remand, which are about 5\%) are not included. The plaintiff win rate is the number of infringement cases where the court judgement favors the patentee divided by the total number of cases. When the FJC reports a judgement in favor of both parties, we treat it as a win for each party and adjust the total appropriately. Estimated standard errors in parentheses are based on the binomial formula. Numbers in bold are statistically significant at the 0.01 level. 
Table 9. Probit Estimation of Litigation Probability: Case filing

\begin{tabular}{|c|c|c|c|c|}
\hline & $\begin{array}{c}\text { Panel } \\
\text { Infringen }\end{array}$ & ents & \multicolumn{2}{|l|}{ Panel B } \\
\hline & Parameter & Marginal & Parameter & Marginal \\
\hline Claims & $\begin{array}{l}\mathbf{0 . 0 2 3} \\
(.001)\end{array}$ & 0.007 & $\begin{array}{l}\mathbf{0 . 0 2 9} \\
(.003)\end{array}$ & 0.002 \\
\hline Claims $^{2}\left(\mathrm{x} 10^{3}\right)$ & $\begin{array}{l}-0.024 \\
(.002)\end{array}$ & & $\begin{array}{l}-0.15 \\
(.038)\end{array}$ & \\
\hline FWD cites/claim & $\begin{array}{l}\mathbf{0 . 1 9} \\
(.008)\end{array}$ & 0.059 & $\begin{array}{l}\mathbf{0 . 2 0} \\
(.017)\end{array}$ & 0.008 \\
\hline$[\text { FWD cites/claim }]^{2} \times 10^{3}$ & $\begin{array}{l}-4.38 \\
(.32)\end{array}$ & & $\begin{array}{l}-5.65 \\
(.83)\end{array}$ & \\
\hline BWD cites/claim & $\begin{array}{l}-\mathbf{- 0 . 0 5 6} \\
(.010)\end{array}$ & -0.017 & $\begin{array}{l}-\mathbf{- 0 . 0 7 2} \\
(.019)\end{array}$ & -0.005 \\
\hline$[\mathrm{BWD} \text { cites } / \text { claim }]^{2} \times 10^{3}$ & $\begin{array}{l}\mathbf{0 . 8 9} \\
(.43)\end{array}$ & & $\begin{array}{l}1.47 \\
(.62)\end{array}$ & \\
\hline FWDSELF & $\begin{array}{l}\mathbf{0 . 5 1} \\
(.058)\end{array}$ & 0.17 & $\begin{array}{l}\mathbf{0 . 6 3} \\
(.10)\end{array}$ & 0.05 \\
\hline BWDSELF & $\begin{array}{l}-0.31 \\
(.08)\end{array}$ & -0.10 & $\begin{array}{l}-0.16 \\
(.15)\end{array}$ & -0.01 \\
\hline NO3USPC & $\begin{array}{l}-\mathbf{- 0 . 0 6 8} \\
(.008)\end{array}$ & -0.022 & $\begin{array}{l}-\mathbf{- 0 . 0 1 4} \\
(.015)\end{array}$ & -0.003 \\
\hline Portsize $\left(\mathrm{x} 10^{3}\right)$ & $\begin{array}{l}-0.104 \\
(.037)\end{array}$ & -0.025 & $\begin{array}{l}-0.21 \\
(.13)\end{array}$ & -0.015 \\
\hline Portsize $^{2}\left(\mathrm{x} 10^{6}\right)$ & $\begin{array}{l}\mathbf{0 . 0 0 9} \\
(.001)\end{array}$ & & $\begin{array}{l}0.005 \\
(.003)\end{array}$ & \\
\hline PortNondrug (x 10³) & $\begin{array}{l}-0.061 \\
(.033)\end{array}$ & -0.021 & $\begin{array}{l}0.056 \\
(.12)\end{array}$ & 0.004 \\
\hline PortUNLIST (x 10³) & $\begin{array}{l}-\mathbf{0 . 0 2 7} \\
(.013)\end{array}$ & -0.009 & $\begin{array}{l}-0.07 \\
(.04)\end{array}$ & -0.005 \\
\hline PortFLIST (x 10³) & $\begin{array}{l}0.001 \\
(.020)\end{array}$ & 0.0003 & $\begin{array}{l}0.05 \\
(.05)\end{array}$ & 0.004 \\
\hline PortDLIST-S (x 10³) & $\begin{array}{l}-0.60 \\
(.27)\end{array}$ & -0.20 & $\begin{array}{r}-0.36 \\
(.41)\end{array}$ & 0.028 \\
\hline Tech. Concentration $(C 4)$ & $\begin{array}{l}-\mathbf{- 4 . 1 7} \\
(.23)\end{array}$ & -1.36 & $\begin{array}{l}-\mathbf{6 . 1 5} \\
(.46)\end{array}$ & -0.48 \\
\hline Relsize $\left(\right.$ x $\left.10^{3}\right)$ & $\begin{array}{l}-3.10 \\
(1.12)\end{array}$ & -1.01 & $\begin{array}{l}-0.91 \\
(2.67)\end{array}$ & -0.07 \\
\hline
\end{tabular}




\section{Infringements Declaratory Judgements}

$\begin{array}{lllll}\text { Variable } & \text { Parameter } & \text { Marginal } & \text { Parameter } & \text { Marginal } \\ \text { FIND } & \mathbf{- 0 . 5 4} & \mathbf{- 0 . 1 2} & \mathbf{- 1 . 8 4} & \mathbf{- 0 . 0 3 6} \\ & (.09) & & (.17) & \\ \text { DIND } & 0.13 & \mathbf{0 . 1 4} & \mathbf{- 1 . 3 0} & \mathbf{0 . 0 1 2} \\ & (.08) & & (.15) & \\ \text { FUNLIST } & \mathbf{- 0 . 6 9} & \mathbf{- 0 . 2 2} & \mathbf{- 1 . 8 1} & \mathbf{- 0 . 0 4 5} \\ & (.08) & & (.15) & \\ \text { DUNLIST } & \mathbf{0 . 2 1} & \mathbf{0 . 1 9} & \mathbf{- 1 . 0 6} & \mathbf{0 . 0 5 8} \\ & (.08) & & (.15) & \\ \text { FLIST } & -0.15 & 0.007 & \mathbf{- 1 . 7 7} & \mathbf{- 0 . 0 3 0} \\ & (.19) & & (.42) & \\ \text { DLIST-S } & \mathbf{0 . 2 7} & \mathbf{0 . 1 7} & \mathbf{0 . 4 6} & \mathbf{0 . 0 6 0} \\ & (.11) & & (.15) & \\ \text { DLIST-B } & \mathbf{- 0 . 2 3} & \mathbf{- 0 . 0 3} & \mathbf{- 0 . 9 8} & \mathbf{- 0 . 0 0 6} \\ & (.08) & & (.20) & \\ \text { No. observations } & 17,443 & & 11,061 & \\ \text { Pseudo-R } & 0.162 & & 0.164 & \\ \chi^{2}(31) & 3858.3 & & 1098.9 & \end{array}$

Conversion Factors to Estimate Population Marginal Effects Technology Field Infringements Declaratory Judgements

Aggregate

Drugs

Other Health

Chemicals

Electronics

Mechanical

Computers

Biotechnology

Miscellaneous
.048

.050

.089

.031

.038

.045

.063

.076

.084
.021

.018

.039

.014

.020

.021

.034

.030

.031

Notes: Estimated standard errors are in parentheses. Numbers in bold are significant at the 0.01 level. The conversion factors are computed as described in Appendix 3. 


\section{Table 10. Predicted Probabilities of Infringement Suits}

$\begin{array}{lccll}\text { Percentile of Distribution } & \mathbf{9 9 t h} & \mathbf{9 5 t h} & \mathbf{9 0 t h} & \mathbf{5 0 t h} \\ \text { Aggregate } & \mathbf{7 . 9} \% & 3.8 \% & 2.8 \% & 0.8 \% \\ \text { Technology Field } & & & & \\ \text { Drugs } & \mathbf{9 . 4} \% & 3.9 \% & 2.8 \% & 0.9 \% \\ \text { Other Health } & \mathbf{1 9 . 5} & 6.1 & 4.5 & 1.7 \\ \text { Chemicals } & \mathbf{4 . 2} & 2.1 & 1.6 & 0.5 \\ \text { Electronics } & \mathbf{7 . 1} & 2.8 & 2.1 & 0.5 \\ \text { Mechanical } & \mathbf{6 . 5} & 2.8 & 2.2 & 0.7 \\ \text { Computers } & \mathbf{1 4 . 8} & 4.5 & 3.4 & 0.6 \\ \text { Biotechnology } & \mathbf{1 2 . 9} & 6.3 & 5.3 & 1.3 \\ \text { Miscellaneous } & \mathbf{8 . 3} & 4.6 & 3.7 & 1.9 \\ \text { Ownership Type } & & & & \\ \text { Domestic Individual } & \mathbf{9 . 4} \% & 4.4 \% & 3.5 \% & 1.9 \% \\ \text { Domestic Unlisted } & \mathbf{1 3 . 7} & 5.9 & 4.2 & 1.9 \\ \text { Small Domestic Listed } & \mathbf{6 . 3} & 5.4 & 4.1 & 1.8 \\ \text { Large Domestic Listed } & \mathbf{4 . 8} & 2.0 & 1.5 & 0.5 \\ \text { Foreign Listed } & \mathbf{2 . 5} & 1.4 & 1.0 & 0.3 \\ \text { Foreign Individual } & \mathbf{4 . 2} & 1.4 & 1.1 & 0.6 \\ \text { Foreign Unlisted } & \mathbf{1 . 4} & 0.8 & 0.7 & 0.3\end{array}$

Notes: The distribution of population probabilities for patents with different characteristics is calculated by first computing the sample probabilities using the parameter estimates for infringement suits in Table 9 . These are then adjusted to reflect population probabilities using Appendix equation (A.3.1). 


\section{References}

[1] Bebchuk, Lucian, 1984, "Litigation and Settlement under Imperfect Information," RAND Journal of Economics. vol. 15, 404-415.

[2] Bernheim, B. Douglas and Michael D Whinston, 1990, "Multimarket Contact and Collusive Behavior," RAND Journal of Economics. vol. 21, issue 1, 1-26.

[3] Cooter, Robert and Daniel Rubinfeld, 1989, "Economic Analysis of Legal Disputes and their Resolution," Journal of Economic Literature, vol. 27, 1067-97.

[4] Ministry of Trade and Industry, 2001,. "Economic Consequences of Legal Expense Insurance for Patents," report prepared for the Danish Patent Office by the Economic Analysis Group. Copenhagen.

[5] Eisenberg, Rebecca, 1999, "Patents and the Progress of Science: Exclusive Rights and Experimental Use," University of Chicago Law Review, vol. 56, 1017-55.

[6] Federal Judicial Center, Federal Court Cases: Integrated Data Base, 1970-89. Ann Arbor, MI: Inter-university Consortium for Political and Social Research. Tapes updated to 1999.

[7] Graham, Stuart, Hall, Bronwyn, Harhoff, Dietmar and David C. Mowery, 2001, "Post-Issue Patent 'Quality Control': A Comparative Study of U.S. Patent Reexaminations and European Patent Oppositions," University of California at Berkeley. Mimeo.

[8] Grindley, Peter and David Teece, 1997, "Managing Intellectual Capital: Licensing and Cross-Licensing in Semiconductors and Electronics," California Management Review. vol. 39, no. 2, 8-41.

[9] Hall, Bronwyn and Rosemarie Zeidonis, 2001, "The Patent Paradox Revisted: An Empirical Study of Patenting in the Semiconductor Industry, 1979-1999," RAND Journal of Economics, vol. 32, issue1, 101-128.

[10] Harhoff, Dietmar and Markus Reitzig, 2000, "Determinants of Opposition against EPO Patent Grants - The Case of Biotechnology and Pharmaceuticals," Muenchen: Ludwig-Maximilians-Universitaet. Mimeo. 
[11] Jaffe, Adam and Manuel Trajtenberg, 1999, "International Knowledge Flows: Evidence from Patent Citations," Economics of Innovation and New Technology, vol. 8, 105-136.

[12] Lanjouw, Jean O., Ariel Pakes and Jonathan Putnam, 1998, "How to Count Patents and Value Intellectual Property: Uses of Patent Renewal and Application Data," Journal of Industrial Economics. vol. XX (December), 405-32.

[13] Lanjouw, Jean O. and Josh Lerner, 2002, "Preliminary Injunctive Relief: Theory and Evidence from Patent Litigation," forthcoming in Journal of Law and Economics.

[14] Lanjouw, Jean O. and Mark Schankerman, 2001, "Characteristics of Patent Litigation: A Window on Competition," RAND Journal of Economics. vol. 32, issue 1, 129-151.

[15] Lerner, Josh, 1994, "The Importance of Patent Scope: An Empirical Analysis," RAND Journal of Economics. vol. 25, 319-333.

[16] Lerner, Josh, 1995, "Patenting in the Shadow of Competitors," Journal of Law and Economics. vol. 38, 463-96.

[17] P'ng, I.P.L., 1983, "Strategic Behavior in Suit, Settlement and Trial," Bell Journal of Economics. vol. 14, 539-550.

[18] Priest, G. and B. Klein, 1984, "The Selection of Disputes for Litigation," Journal of Legal Studies, vol. 13, 1-55.

[19] Schankerman, Mark, 1998, "How Valuable is Patent Protection: Estimates by Technology Field," RAND Journal of Economics. vol. 29, no. 1, 77-107.

[20] Scotchmer, Suzanne, 1991, "Standing on the Shoulders of Giants: Cumulative Research and the Patent Law," Journal of Economic Perspectives. vol. 5, 29-41.

[21] Shapiro, Carl, 2001, "Navigating the Patent Thicket: Cross Licenses, Patent Pools and Standard-Setting," in Adam Jaffe, Joshua Lerner and Scott Stern, eds., Innovation Policy and the Economy (Cambridge: MIT Press for the NBER), vol. 1, pp 119-50. 
[22] Siegelman, Peter and Joel Waldfogel, 1999, "Toward a Taxonomy of Disputes: New Evidence Through the Prism of the Priest/Klein Model," Journal of Legal Studies. vol. 18 , no. $1,101-130$.

[23] Somaya, Deepak, 2001, "My Strategy Says: 'See You in Court!' Determinants of Decisions not to Settle Patent Litigation in Computers and Research Medicines," mimeo. Robert Smith School of Business, University of Maryland.

[24] Spier, Kathryn, 1992, "The Dynamics of Pretrial Negotiation," Review of Economic Studies. vol. 59, no. 1, 93-108.

[25] Waldfogel, Joel, 1998, "Reconciling Asymmetric Information and Divergent Expectations Theories of Litigation," Journal of Law and Economics, vol. XLI (October), 451-476. 